\title{
Coronavirus Disease 2019 (COVID-19) in Children: Prevalence, Diagnosis, Clinical Symptoms, and Treatment
}

This article was published in the following Dove Press journal: International Journal of General Medicine

\author{
Hadi Zare-Zardini (D) ${ }^{1,2}$ \\ Hossein Soltaninejad ${ }^{3}$ \\ Farzad Ferdosian ${ }^{4}$ \\ Amir Ali Hamidieh ${ }^{5}$ \\ Mina Memarpoor-Yazdi ${ }^{6}$ \\ 'Department of Sciences, Farhangian \\ University, Isfahan, Iran; ${ }^{2} \mathrm{Hematology}$ and \\ Oncology Research Center, Shahid \\ Sadoughi Hospital, Shahid Sadoughi \\ University of Medical Sciences, Yazd, Iran; \\ ${ }^{3}$ Stem Cell and Regenerative Medicine \\ Institute, Tehran University of Medical \\ Sciences, Tehran, Iran; ${ }^{4}$ Department of \\ Pediatrics, Shahid Sadoughi University of \\ Medical Sciences, Yazd, Iran; ${ }^{5}$ Pediatric \\ Cell Therapy Research Center, Tehran \\ University of Medical Sciences, Tehran, \\ Iran; ${ }^{6}$ Faculty of Pharmacy, Mashhad \\ University of Medical Sciences, Mashhad, \\ Iran
}

Correspondence: Mina Memarpoor-Yazdi Faculty of Pharmacy, Mashhad University of Medical Sciences, Mashhad, Iran Email memarpooryazdi@gmail.com

\begin{abstract}
In this article, we have reviewed the prevalence, diagnosis, symptoms, and treatment of COVID-19 in children. The incidence of COVID-19 among children under 18 years was $2.1 \%$ based on the reported studies, where the mortality rate in the same age group was $0.2 \%$. No death has been reported in children under 9-years old. There are some articles that report children with COVID-19 having symptoms similar to Kawasaki's disease. In these cases, heart complications were observed. The best markers for diagnosing the severity of the disease in children are the levels of bilirubin and hepatic enzymes. Large number of angiotensin converting enzyme 2 (ACE2) receptors on cell surfaces, effective innate immune system, and high level of blood lymphocyte have been reported to be the potent reasons for lower incidence of severe symptoms of COVID-19 among children. Children can very well be the carriers of this virus. Children with severe COVID-19 clinical symptoms, especially those suffering from pneumonia, must be hospitalized similar to adults, while quarantine is required for those having mild symptoms. Antiviral medication (lopinavir, darunavir, favipiravir, remdesivir, ribavirin, oseltamivir, tocilizumab, and umifenovir), ACE inhibitors, interferon- $\alpha 2 b$, co-therapy with azithromycin, inhaling iNO, and oxygen therapy can be used for treatment. For the treatment of children without any clinical and infection symptoms, home isolation protocol has been recommended.
\end{abstract}

Keywords: COVID-19, coronavirus, SARS-CoV-2, children, angiotensin converting enzyme 2 , infectious

\section{Introduction}

COVID-19 is a viral disease caused by SARS-CoV-2 (severe acute respiratory syndrome coronavirus-2). Coronaviruses are a large family of viruses that cause a variety of diseases, such as SARS, MERS, and COVID-19. ${ }^{1}$ These viruses are mostly present in mammals and birds. However, seven human-transmitted coronaviruses have been discovered so far. ${ }^{2}$ The most recent coronavirus species, SARSCoV-2, was reported in Wuhan, China in December 2019. Common symptoms of COVID-19 are fever, dry cough, and breathing shortness. Muscle aches, sputum production, and sore throat are some of the less common symptoms. ${ }^{3}$ Although the majority of patients show mild symptoms, underlying diseases such as cardiovascular, diabetes, chronic respiratory, and cancer exacerbate COVID-19 effects. ${ }^{1}$ The virus is mainly spread from infected persons through small droplets when coughing or sneezing. ${ }^{4}$ The COVID-19 incubation period is in the range of $2-14$ days. ${ }^{5}$ The mortality rate is estimated to be between 2 and $5 \%$, but varies depending on the 
infected person's age and health condition. ${ }^{6}$ Age is the most important parameter determining the severity of the disease and the mortality rate. ${ }^{5}$ In this review, prevalence, diagnosis, clinical symptoms, and treatment of COVID-19 was reviewed based on a literature review.

\section{Prevalence}

Xiaogan, Hubei province reported the first infected infant (a 3-month-old baby) with fever symptoms on January 26, 2020. ${ }^{7}$ Hereinafter, on January 28, 2020, an infected child case was reported in Wuhan, China, where the COVID-19 outbreak originally took place. ${ }^{8}$ The incidence of COVID-19 in children increased after the condition of disease was reported to be pandemic. ${ }^{7,9,11}$ It was reported that among those infected, $2.1 \%$ of them were children under 18 years old, and no fatality in children under 9 years was reported. ${ }^{1,5}$ Most infected children were infected by family members. Severe disease was only observed in $4.4 \%$ of these children. This agefigure is more than $15 \%$ in adults ${ }^{12}$.

Gender ratio among infected children is reported to be $1: 1$, while in adults the ratio of infected males to females is $1.1:{ }^{2}$ The information recently provided by Chinese Centers for Diseases Control and Prevention has revealed that as of February 11, out of 44,672 patients infected with the virus, 416 individuals $(0.9 \%)$ were at the age of under 10 years old and 549 persons (1.2\%) were between the age of 10 and 18 years. ${ }^{5}$ The average age of children infected with COVID-19 was found to be 6.7 years. Although reports have indicated the prevalence of COVID-19 incidence among children is very low, the number of pediatric patients may increase in the future. ${ }^{6}$ The low COVID-19 incidence among children does not necessarily indicate that they are resistant to the infection. ${ }^{6}$

\section{Reasons for Low COVID-19 Incidence Among Children}

Several reasons have been reported for the low prevalence of COVID-19 among children. One probable reason is low outdoor activities and less international traveling as compared to their parents, which results in their low exposure to viral infection. ${ }^{13}$ On the other hand, children, especially those younger than 10 , possess a more active innate immune response and healthier respiratory tracts. ${ }^{6,14}$ Lower exposure of children to cigarette smoke and air pollution in comparison to their parents reduces their chances of being affected by underlying disorders. ${ }^{15}$ Several studies have indicated that the significant difference in the frequency of COVID-19 in children in comparison to adults has a positive correlation with their exposure rate to the population in public areas. ${ }^{6,16,17}$

There are some reports suggesting that the lower incidence of severe symptoms among children than in adults is attributed not only to their lower exposure to public risk factors but also can be related to immaturity of angiotensin converting enzyme 2 (ACE2) receptors, which are the sites for COVID-19 binding. The most common cited reason for the age-related difference in the incidence of COVID19 is the difference in the distribution, maturation and functioning of viral receptors in children as compared to adults. $^{16}$

The SARS virus, SARS-CoV-2, and human coronavirus-NL63 (HCoV-NL63) use the ACE2 as a receptor on human cells. Studies have indicated that SARS-CoV-2 enters the cells by attaching its spike proteins to ACE2 receptors. Therefore, the number of ACE2 receptors on the surface of the virus directly affects the degree of cells susceptibility to infection. ${ }^{18}$ Studies have indicated that ACE2 plays a critical role in lungs protective mechanisms and can protect lungs against severe injuries caused by viral infection both in experimental mouse models and pediatric patients. ${ }^{19}$

Another study carried out to find the effect of age on the amount of ACE2 in rat lungs has shown that ACE2 expression dramatically decreases with an increase in age. ${ }^{20}$ This finding may not agree with the low sensitivity of children to COVID- $19 .{ }^{20}$ On the other hand, after the virus enters the host cells, it down regulates ACE2, which results in lower cell susceptibility. ${ }^{17}$ Accordingly, ACE2 plays a dual role in cell infection by virus.

Researchers showed that the decrease of leucocytes and lymphocytes might occur in COVID-19 in adults. So, this new virus affects the lymphocytes, especially $\mathrm{T}$ lymphocytes. By induction of cytokine storm and stimulation of immune responses, the changes in leucocytes and lymphocytes can occur. ${ }^{21}$ In some studies, the reduction of lymphocytes has been attributed to inhibition of cellular immune function by virus. But, in children, these laboratory data are in the normal range. ${ }^{22,23}$ Some reports have revealed that the number of lymphocytes in infected children's blood is high in comparison to adults. ${ }^{19}$ In infected adults, a decrease in the number of lymphocytes, known as lymphocytopenia, has been observed while in infected children, the blood lymphocytes level has been shown to be normal. This is due to the higher level of lymphocytes, especially natural killer (NK) cells, in children's blood than in adults. ${ }^{24}$ 
These findings are really helpful in finding out the main reasons of low susceptibility of children to COVID-19.

In some reports, the low incidence of disease has been related to the small number of children sampled. ${ }^{9}$ Development of less intense cytokine storms from the immune systems is another reason for less prevalence of COVID-19 in children. ${ }^{10}$

\section{Diagnosis Tools}

The first diagnostic tool to monitor infected children is the same as used for adults, ie, checking to see if they have had any contact with infected individuals. ${ }^{25}$ The next stage is to swab and take sputum, stool, and blood samples to be tested for COVID-19 nucleic acid using reverse-transcriptase polymerase chain reaction (RT-PCR). ${ }^{13,26}$ Based on review literature, a nasal swab is more sensitive and specific than a pharyngeal swab. Lung imaging examination has been considered as a confirmation complimentary method. Feng et $\mathrm{al}^{27}$ showed that small nodular ground glass opacities like objects were observed in early chest CT images in children infected with COVID-19. CT imaging is more sensitive than RT-PCR analysis. In different studies, results show that in patients with positive CT for COVID-19, initial tests with pharyngeal RT-PCR were negative.

\section{Clinical Symptoms}

Fever, fatigue, dry cough, and upper respiratory symptoms (nasal congestion and running nose) and occasionally gastrointestinal symptoms such as nausea, vomiting, and diarrhea are the main clinical symptoms of COVID-19. ${ }^{3}$ In terms of symptoms, in a study made on 416 children ( $<10$ years old) in China, $76.1 \%$ of infected children had fever and $70.4 \%$ of those showed viral pneumonia-like changes in their chest imaging. ${ }^{28}$ The main symptoms were fever, dry cough, followed by vomiting, diarrhea, and other digestive disorders. ${ }^{25,28}$ In another study, 5.9\% of all pediatric cases were categorized in the class of severe or acute patients, which included children with congenital heart disease, broncho-pulmonary hypoplasia, airway/lung anomalies, and severe malnutrition. However, more studies are needed to support these findings. ${ }^{29}$

Among these symptoms, diarrhea and vomiting are more common in children than in adult patients. Common symptoms in adults infected with COVID-19 are: fever (80-98\%), dry cough $(80 \%)$, and fatigue $(40-60 \%){ }^{30}$ The symptoms in children are more atypical than in adults, and coughing is lighter. ${ }^{31}$ Instead of common symptoms in adults, gastrointestinal involvement (diarrhea, vomiting, etc.) is more common in children. These symptoms are twice as common in children as in adults. ${ }^{9,22}$ These different symptoms may be due to differences in maturity of ACE2. ${ }^{32}$

In Figure 1, the clinical symptoms of COVID-19 in children are arranged based on incidence.

Laboratory tests have shown that blood biochemical indices, such as C-reactive proteins, are in the normal range or slightly increased in infected children. Different studies have shown that the total number of white blood cells in the early stage of the disease is normal or reduced,

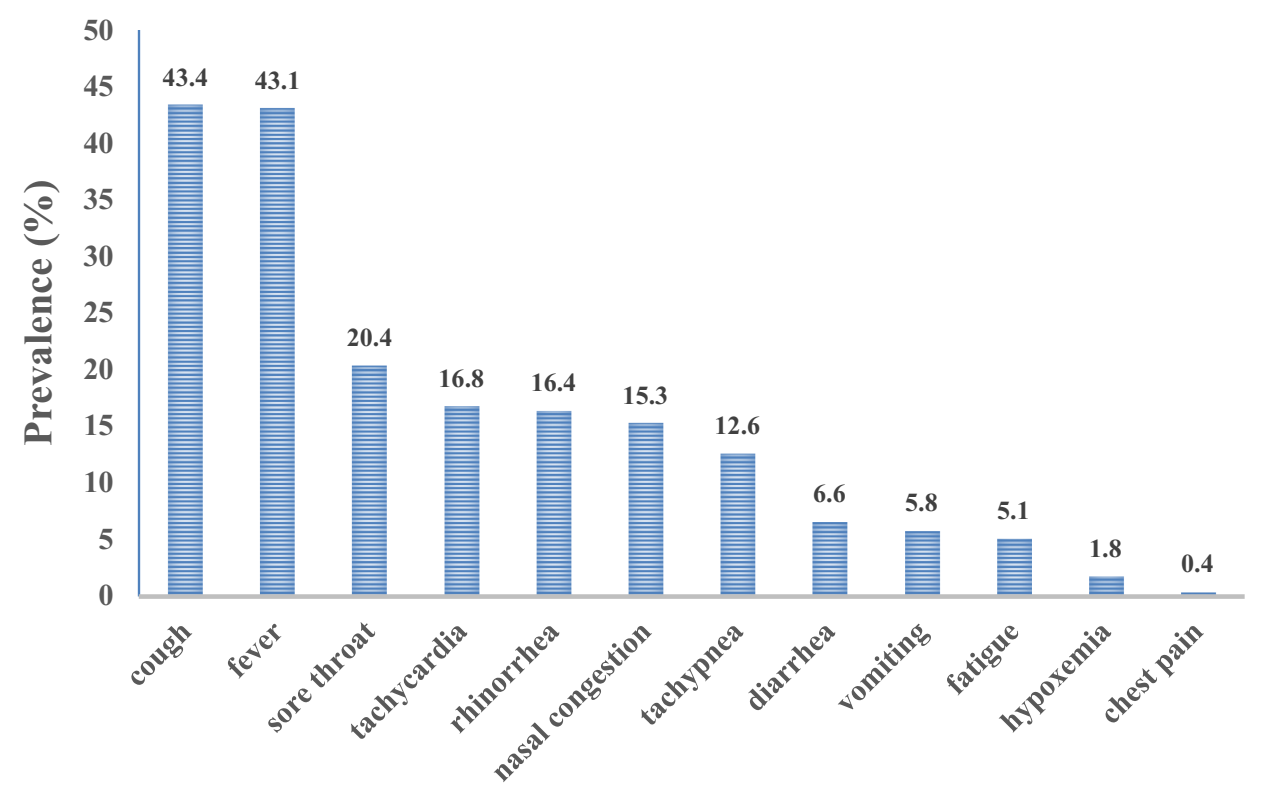

Figure I The prevalence of clinical symptoms of COVID-19 in children. 
or the lymphocyte count is reduced in infected children. Changes in enzymes (creatine kinase-MB (CK-MB), alanine aminotransferase (ALT), aspartate aminotransferase, and lactate dehydrogenase (LDH)) and also in procalcitonin (PCT) are also seen in infected children. The best markers for diagnosing the severity of the disease in children are the levels of bilirubin and hepatic enzymes. ${ }^{13,33,36}$

Lung imaging examination of infected children has revealed a mild increase in lung markings or groundglass opacity or pneumonia. However, whether children were less susceptible to SARS-CoV-2, or their affliction was mostly asymptomatic or difficult to detect, remains unclear. $^{13,33,36}$

It is possible to divide all pediatric patients into five groups based on their clinical features:

1) Simple infection: in this group, it is manifested as fever, cough, sore throat, nasal congestion, fatigue, headache, myalgia, or discomfort, without sepsis or shortness of breath. An infection without clinical symptoms is referred to as latent infection.

2) Mild pneumonia: manifested as fever and cough. Chest radiographs have shown changes in lung inflammation, without severe pneumonia, such as dyspnea and shortness of breath.

3) Severe pneumonia: fever, cough, accompanied by difficulty in breathing or shortness of breath $(<2$ months old: breathing $\geq 60$ breaths/min; $2 \sim 12$ months old: breathing $\geq 50$ breaths/min; 1 5 years old: breathing $\geq 40$ times $/ \mathrm{min}$ ), Severe respiratory failure such as wheezing, severe respiratory trident sign; difficulty in feeding, and convulsions.

4) Acute respiratory distress syndrome (ARDS): New symptoms or existing clinical symptoms are manifested within 1-week, respiratory symptoms worsen; lungs show ground glass shadowlike images. The degree of ARDS can be judged according to the oxygenation index or the pulse oxygen saturation index.

5) Septic shock: anemia, changes in consciousness; bradycardia or tachycardia or dilated blood vessels with weak pulse; Shortness of breath; skin spots, purpura rash, or ecchymosis; elevated blood lactate; oliguria; hyperthermia or hypothermia. ${ }^{11,37,40}$

In late April 2020, there were some articles that reported children with COVID-19 had symptoms similar to Kawasaki's disease. In this state, heart complications have been reported. ${ }^{41}$ Researchers have shown that this disease might be incorporated as some complication of COVID-19 in pediatric patients. ${ }^{42,44}$ In Feldstein et al's ${ }^{42}$ study, their results have shown that $33 \%$ of the diagnosed infected children had Kawasaki's disease-like clinical symptoms. These patients were younger than 5 years old, similar to patients reported for Kawasaki disease.

Briefly, based on a literature review, common clinical symptoms (fever or pneumonia) may occur in a low frequency among children. In most of the reported pediatric cases, obvious clinical symptoms and abnormal CT findings have rarely been observed. Nevertheless, acute respiratory distress syndromes, septic shock, metabolic acidosis, and blood coagulation dysfunctions may be observed in children with severe disease.

\section{Treatment}

For the treatment of children without any clinical and infection symptoms, home isolation for a 2 weeks protocol has been recommended in order to terminate the virus shedding. ${ }^{45}$ During these 2 weeks, the use of supportive care such as drugs that reduce the clinical symptoms of the disease is essential and unavoidable. At this stage, it is not necessary to use antiviral drugs. ${ }^{45}$

Based on a new literature review, most children show mild clinical and biochemical signs. There is no fever or severe pneumonia in infected children. The mean recovery time for pediatric patients is estimated to be between $1-2$ weeks. ${ }^{15,46}$

Antiviral therapy (interferons, lopinavir/ritonavir, umifenovir, remdesivir, and oseltamivir) has been used for the treatment of COVID-19 in adults. However, antiviral therapy has not been recommended for children showing mild symptoms of respiratory viral infection. ${ }^{47}$ The best therapy is the application of Interferon- $\alpha 2 b$. Based on Chen et al's study, the following protocol can be used:

1) Interferon- $\alpha 2 \mathrm{~b}$ nebulization, $100,000-200,000 \mathrm{IU} / \mathrm{kg}$ for mild cases, and 200,000-400,000 IU/ $\mathrm{kg}$ for severe cases, two times/day for 5-7 days.

2) Lopinavir/litonavir $(200 \mathrm{mg} / 50 \mathrm{mg})$. The recommended doses: weight $7-15 \mathrm{~kg}, 12 \mathrm{mg} / 3 \mathrm{mg} / \mathrm{kg}$; weight $15-40 \mathrm{~kg}, 10 \mathrm{mg} / 2.5 \mathrm{mg} / \mathrm{kg}$; weight $>40 \mathrm{~kg}, 400 \mathrm{mg} /$ $100 \mathrm{mg}$ as adult each time, twice a day for $1-2$ weeks. ${ }^{38}$

3) Prescribed ribavirin (10-15 $\mathrm{mg} / \mathrm{kg}$ a day) in addition to interferon. ${ }^{10}$

Antimalarial drugs, eg, hydroxychloroquine, have been used in children with moderate-to-severe 2019-nCoV pneumonia. Karimi et $\mathrm{al}^{45}$ have presented an algorithmic approach for the treatment of childrssssen. In this algorithm, hydroxychloroquine has a special place. But, in recent months, articles suggest that hydroxychloroquine is detrimental and should not be used. Based on a WHO report on June 17, 2020, hydroxychloroquine treatment 
does not result in mortality reduction in hospitalized COVID-19 patients, when compared with standard care. ${ }^{48}$

Corticosteroids should be avoided in the common type of infection. This therapy can be used in children with rapidly deteriorating chest imaging and the occurrence of ARDS, obvious toxic symptoms, encephalitis or encephalopathy, hemophagocytic syndrome and other serious complications, septic shock, and obvious wheezing symptoms. ${ }^{6,38,49}$

Inhaling nitric oxide (iNO) has been suggested for treatment of children with COVID-19 pneumonia. This agent improves severe hypoxia, and shortens the duration of ventilatory support.

In children with mild-to-severe symptoms, oxygen therapy such as nasal catheters or oxygen masks should be applied due to changes in blood oxygen saturation. In children with ineffective breathing and oxygen therapy, high oxygen flow catheter inhalation (HFNO) or non-invasive ventilation (NIV) should be used. ${ }^{30}$ There are some potential treatments including: monoclonal antibodies, protease inhibitors, and RNA synthesis inhibitors such as similar treatment for other similar coronaviruses. ${ }^{50}$ In cases with chest infection, the use of antibiotics such as azithromycin can be used for control and prevention of secondary infections and inflammatory condition. ${ }^{51}$

\section{Conclusion}

Based on this review, COVID-19 is a disease with different severity symptoms in children and in adults. Most of the infections in children are familial clusters with mild clinical symptoms. The fatality rate due to COVID-19 infection is very low in children. Children are the most important carriers of COVID-19 due to the absence of clear clinical symptoms in them. Early isolation should be performed to protect children with underlying diseases. Antiviral medications (lopinavir, darunavir, favipiravir, remdesivir, ribavirin, oseltamivir, tocilizumab, and umifenovir), ACE inhibitors, interferon- $\alpha 2 b$, co-therapy with azithromycin, inhaling iNO, and oxygen therapy can be used for treatment.

\section{Acknowledgments}

The authors thank Professor Bahman Kholdebarin, Department of Biology, Shiraz University, for his assistance in editing this manuscript.

\section{Funding}

There is no funding to report.

\section{Disclosure}

The authors declare no conflict of interest.

\section{References}

1. Cai J, Xu J, Lin D, et al. A case series of children with 2019 novel coronavirus infection: clinical and epidemiological features. Clin Infect Dis. 2020.

2. Liu W, Zhang Q, Chen J, et al. Detection of covid-19 in children in early january 2020 in Wuhan, China. $N$ Engl J Med. 2020;382 (14):1370-1371. doi:10.1056/NEJMc2003717

3. Matthai J, Shanmugam N, Sobhan P. Coronavirus disease (COVID-19) and the gastrointestinal system in children. Indian Pediatr. 2020;57(6):533-535. doi:10.1007/s13312-020-1851-5

4. Chua M, Lee J, Sulaiman S, Tan H. From the frontline of COVID19 - how prepared are we as obstetricians: a commentary. BJOG. 2020;127(7):786-8.

5. Lee P-I, Hu Y-L, Chen P-Y, Huang Y-C, Hsueh P-R. Are children less susceptible to COVID-19? J Microbiol Immunol Infect. 2020;53 (3):371-372. doi:10.1016/j.jmii.2020.02.011

6. Lu Q, Shi Y. Coronavirus disease (COVID-19) and neonate: what neonatologist need to know. J Med Virol. 2020;92(6):564-567. doi:10.1002/jmv.25740

7. Zhang Y, Lin D, Xiao M, et al. 2019-novel coronavirus infection in a three-month-old baby. Zhonghua Er Ke Za Zhi. 2020;58:E006.

8. Cui X, Zhang T, Zheng J, et al. Children with coronavirus disease 2019: a review of demographic, clinical, laboratory, and imaging features in pediatric patients. J Med Virol. 2020. doi:10.1002/ jmv. 26023

9. Huang C, Wang Y, Li X, et al. Clinical features of patients infected with 2019 novel coronavirus in Wuhan, China. Lancet (London). 2020;395(10223):497-506. doi:10.1016/S0140-6736(20)30183-5

10. Su L, Ma X, Yu H, et al. The different clinical characteristics of corona virus disease cases between children and their families in China - the character of children with COVID-19. Emerg Microbes Infect. 2020;9(1):707-713. doi:10.1080/22221751.2020.1744483

11. Xing YH, Ni W, Wu Q, et al. Prolonged viral shedding in feces of pediatric patients with coronavirus disease 2019. J Microbiol Immunol Infect. 2020;53(3):473-480. doi:10.1016/j.jmii.2020.03.021

12. Wu Z, McGoogan JM. Characteristics of and important lessons from the coronavirus disease 2019 (COVID-19) outbreak in China: summary of a report of 72314 cases from the Chinese center for disease control and prevention. JAMA. 2020;323(13):1239-1242. doi:10.10 01/jama.2020.2648

13. Tan X, Huang J, Zhao F, Zhou Y, Li JQ, Wang XY. Clinical features of children with SARS-CoV-2 infection: an analysis of 13 cases from Changsha, China. Zhongguo Dang Dai $\mathrm{Er} \quad \mathrm{Ke} \quad \mathrm{Za} \quad$ Zhi. 2020;22:294-298.

14. Shahabi F, Mosaddeghi P, Negahdaripour M, et al. Therapeutic Approaches for COVID-19 Based on the Dynamics of InterferonMediated Immune Responses. 2020.

15. Brodin P. Why is COVID-19 so mild in children? Acta Paediatr. 2020;109(6):1082-1083. doi:10.1111/apa.15271

16. Cristiani L, Mancino E, Matera L, et al. Will children reveal their secret? The coronavirus dilemma. Eur Respir J. 2020;55(4):2000749. doi:10.1183/13993003.00749-2020

17. Skarstein Kolberg E. ACE2, COVID19 and serum ACE as a possible biomarker to predict severity of disease. $J$ Clin Virol. 2020;126:104350. doi:10.1016/j.jcv.2020.104350

18. Ciaglia E, Vecchione C, Puca AA. COVID-19 infection and circulating ACE2 levels: protective role in women and children. Front Pediatr. 2020;8. doi:10.3389/fped.2020.00206

19. Lee P-I, Hu Y-L, Chen P-Y, Huang Y-C, Hsueh P-R. Are children less susceptible to COVID-19? J Microbiol Immunol Infect. 2020; S1684-1182(1620)30039-30036. 
20. Xie X, Chen J, Wang X, Zhang F, Liu Y. Age- and gender-related difference of ACE2 expression in rat lung. Life Sci. 2006;78 (19):2166-2171. doi:10.1016/j.lfs.2005.09.038

21. Liu WJ, Zhao M, Liu K, et al. T-cell immunity of SARS-CoV: implications for vaccine development against MERS-CoV. Antiviral Res. 2017;137:82-92. doi:10.1016/j.antiviral.2016.11.006

22. Chen N, Zhou M, Dong X, et al. Epidemiological and clinical characteristics of 99 cases of 2019 novel coronavirus pneumonia in Wuhan, China: a descriptive study. Lancet (London). 2020;395 (10223):507-513. doi:10.1016/S0140-6736(20)30211-7

23. Feng K, Yun YX, Wang XF, et al. Analysis of CT features of 15 children with 2019 novel coronavirus infection. Zhonghua Er Ke Za Zhi. 2020;58:E007.

24. Wei M, Yuan J, Liu Y, Fu T, Yu X, Zhang Z-J. Novel coronavirus infection in hospitalized infants under 1 year of age in China. JAMA. 2020;323(13):1313-1314. doi:10.1001/jama.2020.2131

25. Wang XF, Yuan J, Zheng YJ, et al. Retracted: clinical and epidemiological characteristics of 34 children with 2019 novel coronavirus infection in Shenzhen. Zhonghua Er Ke Za Zhi. 2020;58:E008.

26. Paret M, Lighter J, Pellett Madan R, Raabe VN, Shust GF, Ratner AJ. SARS-CoV-2 infection (COVID-19) in febrile infants without respiratory distress. Clin Infect Dis. 2020. doi:10.1093/cid/ciaa452

27. Feng K, Yun YX, Wang XF, et al. Analysis of CT features of 15 children with 2019 novel coronavirus infection. Zhonghua Er Ke Za Zhi. 2020;58(4):275-278. doi:10.3760/cma.j.cn112140-2020021000071

28. Yang P, Liu P, Li D, Zhao D. Corona virus disease 2019, a growing threat to children? J Infect Dis. 2020.

29. Onder G, Rezza G, Brusaferro S. Case-fatality rate and characteristics of patients dying in relation to COVID-19 in Italy. JAMA. 2020. doi:10.1001/jama.2020.4683

30. Hong H, Wang Y, Chung H-T, Chen C-J. Clinical characteristics of novel coronavirus disease 2019 (COVID-19) in newborns, infants and children. Pediatr Neonatol. 2020;61(2):e2. doi:10.1016/j. pedneo.2020.03.001

31. Qiu H, Wu J, Hong L, Luo Y, Song Q, Chen D. Clinical and epidemiological features of 36 children with coronavirus disease 2019 (COVID-19) in Zhejiang, China: an observational cohort study. Lancet Infect Dis. 2020;20(6):689-696. doi:10.1016/S14733099(20)30198-5

32. Fang F, Luo X. Facing the pandemic of 2019 novel coronavirus infections: the pediatric perspectives. Zhonghua $\mathrm{Er} \mathrm{Ke} \mathrm{Za} \mathrm{Zhi.}$ 2020;58:E001.

33. Henry BM, Lippi G, Plebani M. Laboratory abnormalities in children with novel coronavirus disease 2019. Clin Chem Lab Med. 2020;58 (7):1135-1138. doi:10.1515/cclm-2020-0272

34. Hu Z, Song C, Xu C, et al. Clinical characteristics of 24 asymptomatic infections with COVID-19 screened among close contacts in Nanjing, China. Sci China Life Sci. 2020;63(5):706-711. doi:10.10 07/s11427-020-1661-4

35. Xu G, Yang Y, Du Y, et al. Clinical pathway for early diagnosis of COVID-19: updates from experience to evidence-based practice. Clin Rev Allergy Immunol. 2020;59(1):89-100. doi:10.1007/s12016-02008792-8

International Journal of General Medicine

\section{Publish your work in this journal}

The International Journal of General Medicine is an international, peer-reviewed open-access journal that focuses on general and internal medicine, pathogenesis, epidemiology, diagnosis, monitoring and treatment protocols. The journal is characterized by the rapid reporting of reviews, original research and clinical studies
36. Tan YP, Tan BY, Pan J, Wu J, Zeng SZ, Wei HY. Epidemiologic and clinical characteristics of 10 children with coronavirus disease 2019 in Changsha, China. J Clin Virol. 2020;127:104353. doi:10.1016/j. jcv.2020.104353

37. Duan YN, Zhu YQ, Tang LL, Qin J. CT features of novel coronavirus pneumonia (COVID-19) in children. Eur Radiol. 2020;30 (8):4427-4433. doi:10.1007/s00330-020-06860-3

38. Zheng F, Liao C, Fan QH, et al. Clinical characteristics of children with coronavirus disease 2019 in Hubei, China. Curr Med Sci. 2020;40(2):275-280. doi:10.1007/s11596-020-2172-6

39. Zhou Y, Yang GD, Feng K, et al. Clinical features and chest CT findings of coronavirus disease 2019 in infants and young children. Zhongguo Dang Dai Er Ke Za Zhi. 2020;22(3):215-220.

40. Zhu L, Wang J, Huang R, et al. Clinical characteristics of a case series of children with coronavirus disease 2019. Pediatr Pulmonol. 2020;55(6):1430-1432. doi:10.1002/ppul.24767

41. Hong H, Wang Y, Chung HT, Chen CJ. Clinical characteristics of novel coronavirus disease 2019 (COVID-19) in newborns, infants and children. Pediatr Neonatol. 2020;61(2):131-132.

42. Feldstein LR, Rose EB, Horwitz SM, et al. Multisystem inflammatory syndrome in U.S. children and adolescents. N Engl J Med. 2020. doi:10.1056/NEJMoa2021680

43. Jones VG, Mills M, Suarez D, et al. COVID-19 and kawasaki disease: novel virus and novel case. Hosp Pediatr. 2020;10(6):537-540. doi:10.1542/hpeds.2020-0123

44. Toubiana J, Poirault C, Corsia A, et al. Kawasaki-like multisystem inflammatory syndrome in children during the covid-19 pandemic in Paris, France: prospective observational study. BMJ. 2020;369: m2094. doi:10.1136/bmj.m2094

45. Karimi A, Rafiei Tabatabaei S, Rajabnejad M, et al. An algorithmic approach to diagnosis and treatment of coronavirus disease 2019 (COVID-19) in children: Iranian expert's consensus statement. Arch Pediatr Infect Dis. 2020;8:e102400.

46. Lee P-I, Hu Y-L, Chen P-Y, Huang Y-C, Hsueh P-R. Are children less susceptible to COVID-19? J Microbiol Immunol Infect. 2020.

47. Rahimzadeh G, Ekrami Noghabi M, Kadkhodaei Elyaderani F, et al. COVID-19 infection in iranian children: a case series of 9 patients. J Pediatr Rev. 2020;8:139-144. doi:10.32598/jpr.8.2.139

48. Available from: https://www.who.int/news-room/q-a-detail/q-a-hy droxychloroquine-and-covid-19.

49. Brough HA, Kalayci O, Sediva A, et al. Managing childhood allergies and immunodeficiencies during respiratory virus epidemics - the 2020 COVID-19 pandemic: a statement from the EAACI-section on pediatrics. Pediatr Allergy Immunol. 2020;31(5):442-448. doi:10.11 11/pai.13262

50. Sankar J, Dhochak N, Kabra SK, Lodha R. COVID-19 in children: clinical approach and management. Indian J Pediatr. 2020;87 (6):433-442. doi:10.1007/s12098-020-03292-1

51. Chen ZM, Fu JF, Shu Q, et al. Diagnosis and treatment recommendations for pediatric respiratory infection caused by the 2019 novel coronavirus. World J Pediatr. 2020;16(3):240-246. doi:10.1007/ s12519-020-00345-5

across all disease areas. The manuscript management system is completely online and includes a very quick and fair peer-review system, which is all easy to use. Visit http://www.dovepress.com/ testimonials.php to read real quotes from published authors. 